\title{
PEMBUATAN DAN UJI ORGANOLEPTIK SEDIAAN LULUR TRADISIONAL KAYA ANTIOKSIDAN DARI DAUN KELOR (Moringa oleifera) DAN TEPUNG BERAS KETAN HITAM (Oryza sativa var glutinosa) DENGAN PENAMBAHAN KULIT JERUK NIPIS (Citrus aurantifolia)
}

\author{
Tella Lestari ${ }^{*}$, Agus Djamaluddin², Reti Puji Handayani ${ }^{3}$ \\ ${ }^{1}$ Sekolah Tinggi Ilmu Kesehatan Holistik \\ *Korespondensi: Jl.Veteran No. 272 Ciseureuh Purwakarta, Email : lestaritella09@gmail.com
}

\begin{abstract}
ABSTRAK
Latar Belakang: Lulur tradisional merupakan sediaan kosmetik yang berasal dari bahan alami segar atau bahan yang sudah dikeringkan. Seiring peningkatan pemahaman "back to nature" maka terjadi peningkatan permintaan bahan alami kosmetik yang mengandung antioksidan tinggi, salah satunya daun kelor dengan kandungan tannin dengan penambahan tepung beras ketan hitam dan kulit jeruk nipis sebagai bahan tambahan pada lulur tradisional.
\end{abstract}

Tujuan Penelitian: Membuat sediaan lulur tradisional dari daun kelor dan tepung beras ketan hitam dengan penambahan kulit jeruk nipis, serta membuat sediaan yang stabil melalui uji organoleptik dan mengetahui uji kesukaan.

Metode: Menggunakan desain penelitian tindakan (action research) untuk mengidentifikasi dan menemukan solusi dari sebuah masalah yang diteliti. Alur penelitian dimulai dari perencanaan, action, observasi dan refleksi (perbaikan). Variabel bebas penelitian ini yaitu daun kelor dan tepung beras ketan hitam dengan penambahan kulit jeruk nipis sebanyak (1,3g:2g:6g); (1,3g:2g:7g) dan (1,3g:2g:8g) dengan pengamatan suhu penyimpanan yang berbeda. Variabel terikat yaitu sifat fisik lulur tradisional yang dilihat dari warna, aroma dan tekstur serta kesukaan panelis. Pengumpulan data menggunakan metode observasi untuk uji organoleptik yang dilakukan oleh 20 panelis.

Hasil: Hasil penelitian menunjukkan secara organoleptik sediaan lulur tradisional stabil selama 3 minggu penyimpanan. Dan hasil uji kesukaan ketiga formulasi, diperoleh F3 yang paling disukai dalam penyimpanan di suhu dingin dengan komposisi daun kelor 1,3g, tepung beras ketan hitam $2 \mathrm{~g} \&$ kulit jeruk nipis $8 \mathrm{~g}$ dengan kriteria beraroma jeruk nipis, berwarna hijau kecoklatan, lulur mudah dilepas ketika digosok, bertekstur kasar dan dapat mengangkat kotoran pada permukaan kulit).

Simpulan: Hasil penelitian uji organoleptik dan uji kesukaan yang dilakukan pada ketiga formulasi tersebut dapat dikatakan stabil.

Kata kunci: Daun kelor, tepung beras ketan hitam, kulit jeruk nipis, lulur tradisional, antioksidan.

\footnotetext{
ABSTRACT

Background: Traditional scrubs are cosmetic preparations originating from fresh natural ingredients or dried materials. As the "back to nature" understanding is an increase in the demand for natural ingredients of cosmetics containing high antioxidants, one of which is the kelor leaf with tannin content with the addition of black sticky rice flour and lime skin as an additional material on traditional scrubs.

Research Objectives: Make traditional scrub preparations from Moringa leaves and black sticky rice flour with the addition of lime leather, and make a stable preparation through organoleptic testing and knowing the favorite test.
} 
Method: Using action research design (Action Research) to identify and find solutions from a problem studied. The research flow starts from planning, action, observation and reflection (repairs). The independent variables of this study are melor leaves and black sticky rice flour with as many as the edge of lime (1.3g: $2 g: 6 g) ;(1.3 g: 2 g: 7 g)$ and (1.3g: $2 g: 8 g$ ) with different storage temperature observations.

The dependent variable is the physical properties of traditional scrubs seen from the color, aroma and texture and the favorite of panelists. Data collection uses the observation method for organoleptic tests carried out by 20 panelists.

Results: The results of the study showed organoleptic traditional stable dosage for 3 weeks of storage. And the results of the three formulations of the formulation, obtained by the most preferred F3 in storage at cold temperatures with a composition of the $1.3 \mathrm{~g}$ Moringa leaf composition, $2 G$ black sticky rice flour \& Lime Limit $8 G$ with lime scented criteria, brownish green, the scrub is easily removed when rubbed, re-textured and can lift dirt on the surface of the skin).

Conclusion: The results of organoleptic testing and the preference test carried out in the three formulations can be said to be stable.

Keywords: Moringa leaves, black sticky rice flour, lime leather, traditional scrubs, antioxidants.

\section{PENDAHULUAN}

Perawatan kulit tubuh seperti lulur digunakan untuk tujuan memelihara dan merawat kehalusan kulit serta mencerahkan kulit agar tidak kusam. Kerusakan pada kulit akan mengganggu kesehatan manusia maupun penampilan sehingga kulit perlu dijaga dan dilindungi kesehatannya. Salah satu yang dapat menyebabkan kerusakan kulit adalah radikal bebas yang berupa sinar ultra violet [1]. Menurut penelitian lain, dalam keadaan normal, radikal bebas yang diproduksi didalam tubuh dapat dinetralisir oleh antioksidan yang berasal dari dalam tubuh. Bila kadar radikal bebas terlalu tinggi karena pengaruh dari luar tubuh seperti polusi udara, asap rokok dan aktivitas fisik berat maka antioksidan dalam tubuh tidak mampu lagi menetralisir sehingga dibutuhkan antioksidan dari luar tubuh [2]. Solusi untuk melindungi kulit dari radikal bebas adalah antioksidan, oleh karena itu penting dilakukan perawatan tubuh dari luar dengan melakukan luluran. Salah satunya bahan alami kaya akan antioksidan untuk lulur yaitu daun kelor, karena daun kelor mempunyai kandungan tannin yang berkhasiat sebagai antioksidan akami khususnya pada daun kelor [3].

Lulur tradisional menggunakan bahan-bahan yang alami sehingga sangat aman dan menghasilkan hasil yang natural.
Lulur atau luluran dikenal para wanita Indonesia sebagai salah satu proses untuk membersihkan sekaligus menjaga kecantikan kulit. Tradisi membuat lulur dengan meramu bahan alami seperti rempah-rempah, buah-buahan dan bahan lainnya telah lama dikenal turun-temurun dari berbagai generasi dan kini menjadi lebih dikenal terutama oleh wisatawan mancanegara yang datang ke Indonesia.

Bahan lulur tradisional dapat diperkaya dengan bahan tambahan yang mengandung senyawa fungsional dan mempunyai manfaat hampir sama sebagai antioksidan. Bahan yang digunakan dalam lulur tradisional tidak harus mempunyai harga yang mahal. Salah satu bahan tersebut adalah daun kelor. Kelor adalah salah satu tanaman yang mempunyai banyak manfaat dan biasanya banyak digunakan untuk pendamping makanan, selain itu juga dapat digunakan sebagai bahan dasar kosmetik. Kelor berasal dari Moringa oleifera mempunyai kandungan tannin yang berkhasiat sebagai antioksidan alami khususnya pada daun kelor [3] Hasil uji fitokimia, daun kelor menunjukkan adanya tannin, alkaloid, flavonoid, saponin, antarquinon, steroid dan triterpenoid yang berperan sebagai antioksidan [4]. Penelitian lain juga membuktikan kandungan $\beta$ sitosterol $(90 \mathrm{mg} / \mathrm{g})$, total fenolik $(8 \mu \mathrm{g} / \mathrm{ml})$ 
dan flavonoid $(27 \mu \mathrm{g} / \mathrm{ml})$ pada daun kelor senyawa-senyawa tersebut berhubungan dengan aktivitas antioksidan [5].

Antioksidan merupakan suatu senyawa yang membantu melindungi tubuh dari kerusakan sel-sel oleh radikal bebas. Selain itu, juga berperan memperlambat proses penuaan dengan membantu menggantikan sel-sel tubuh pada tingkat yang lebih cepat dari usianya. Manfaat antioksidan tersebut salah satunya sangat cocok untuk diaplikasikan pada sediaan kosmetika untuk melindungi kulit dari bahaya radikal bebas. Seiring dengan peningkatan pemahaman tentang back to nature maka terjadi peningkatan pula akan permintaan bahan alami yang mengandung antioksidan tinggi. Salah satu alternatif bahan alam lokal di Indonesia yang berpotensi mengandung antioksidan adalah beras.

Bahan tambahan dari lulur tradisional yaitu beras ketan hitam yang merupakan salah satu jenis beras yang berwarna ungu pekat mendekati hitam dan mengandung senyawa fenolik yang tinggi terutama antosianin [6].

Tepung ketan merupakan tepung yang terbuat dari beras ketan hitam atau putih, dengan cara digiling/ditumpuk/dihaluskan. Tepung ketan hitam teksturnya mirip tepung beras, tetapi lebih berat melekat. Untuk membedakan dengan tepung beras, larutkan dengan sedikit air. Larutan tepung beras akan lebih encer sedangkan larutan tepung ketan akan lebih kental. Hal ini disebabkan tepung ketan lebih banyak mengandung pati yang berperekat.

Kulit jeruk nipis merupakan limbah jeruk nipis (Citrus aurantifolia), yang memiliki aroma yang segar dan sejumlah zat yang bermanfaat. Kulit jeruk nipis mengandung semacam minyak atsiri yang pahit rasanya. Minyak atsiri adalah sejenis minyak yang mudah menguap pada suhu kamar dan baunya segar. Minyak atsiri yang berasal dari kulit jeruk nipis dikenal dengan nama minyak sitrun atau citroen oile. Minyak ini mengandung zat kimiawi citrol sebanyak 7,5\%. Kadar minyak atsiri dari kulit jeruk nipis adalah 1,8\%. Pada kulit jeruk nipis juga dijumpai vitamin $\mathrm{C}$ yang dapat menyerap minyak dari kulit dan mengangkat sel kulit mati sehingga kulit terlihat lebih bersih, lembut dan cerah [7].

\section{METODE PENELITIAN}

\section{Waktu dan Tempat Penelitian}

Penelitian ini dilaksanakan di STIKes Holistik Purwakarta yang berlokasi di Jl.Veteran No. 272, Ciseureuh, kec. Purwakarta, kab. Purwakarta. Jawa Barat. Dalam penelitian ini penulis membuat dan meneliti sediaan lulur yang berjudul "Pembuatan Dan Uji Organoleptik Sediaan Lulur Tradisional Kaya Antioksidan Dari Daun Kelor (Moringa oleifera) dan Tepung Beras Ketan Hitam (Oryza Sativa var glutinosa) Dengan Penambahan Kulit Jeruk Nipis (Citrus Aurantifolia)".

\section{Desain dan Jenis Penelitian}

Desain penelitian yang digunakan yaitu action research atau penelitian tindakan karena penelitian ini melakukan tindakan yang berbeda yang meliputi perencanaan (menyiapkan bahan yang akan dibuat sediaan lulur bubuk dari daun kelor, tepung beras ketan hitam dan kulit jeruk nipis, dan menyiapkan alat-alat yang akan digunakan), tindakan (daun kelor, beras ketan hitam dan kulit jeruk nipis dilakukan proses pengeringan dengan sinar matahari langsung lalu setelah semua bahan kering, diblender dan diayak sampai halus setelah semua bahan sudah menjadi bubuk dilakukan proses susut pengeringan untuk mengetahui kadar air simplisia dari daun kelor dan kulit jeruk nipis memenuhi syarat atau tidak, selanjutnya daun kelor, tepung beras ketan hitam dan kulit jeruk nipis ditimbang dengan masing-masing formula daun kelor 1,3 gram, tepung beras ketan hitam 2 gram dan kulit jeruk nipis 6 gram pada F1, kulit jeruk nipis 7 gram pada F2 dan kulit jeruk nipis 8 gram pada F3), observasi (melakukan pengamatan dan mencatat hasil dari uji organoleptik danuji kesukaan pada F1, F2 dan F3) dan refleksi atau perbaikan (setelah mengetahui hasil dari yang diamati kurang stabil, maka dilakukan perbaikan dengan mengulangi proses pembuatan sampai sediaan tersebut stabil). Jenis penelitian yang digunakan yaitu observasi karena peneliti hanya mengamati, melihat dan mencatat hasil uji fisik yaitu uji stabilitas 
organoleptik, dan uji kesukaan lulur tradisional kaya antioksidan dari daun kelor dan tepung beras ketan hitam dengan penambahankulitjeruknipis.

\section{HASIL PENELITIAN}

Penelitian ini dilakukan di Laboratorium STIKes Holistik Purwakarta pada bulan Juli sampai Agustus 2020.Bahan yang diperlukan dalam membuat lulur tradisional dari bahan alam yaitu daun kelor, beras ketan hitam, dan kulit jeruk nipis. Daun kelor (Moringa oleifera) yang digunakan diperoleh langsung dari daerah Kp. Cibeunying RT/RW 18/08 Desa Wantilan Kecamatan Cipeundeuy Kabupaten Subang.

Bagian yang digunakan adalah daun yang muda dan tidak ada bercak-bercak kuning. Beras ketan hitam (Oryza sativa var glutinosa) dan kulit jeruk nipis (Citrus aurantifolia) didapatkan di salah satu penjual di Pasar Cipeundeuy dan hanya sebagai bahan tambahan.

Bahan yang sudah didapatkan kemudian dicuci bersih menggunakan air mengalir. Tahap selanjutnya daun kelor (Moringa oleifera) dikeringkan dengan sinar matahari langsung sampai kering dan dihaluskan, untuk beras ketan hitam (Oryza sativa var glutinosa) setelah dicuci bersih lalu direndam sehari semalam dan dikeringkan kurang lebih 3 jam lalu dihaluskan, selanjutnya kulit jeruk nipis (Citrus aurantifolia) dikeringkan selama 5 jam sampai kering lalu dihaluskan. Untuk daun kelor, beras ketan hitam dan kulit jeruk nipis setelah proses pengeringan dengan sinar matahari langsung, dilakukan penghancuran dengan menggunakan blender sampai halus. Bahan simplisia yang sudah dihaluskan daun kelor dan kulit jeruk nipis dilakukan penimbangan dan susut pengeringan dengan masing-masing petri disterilkan terlebih dahulu dengan cara masukkan kedalam oven 105을 selama 30 menit setelah itu dimasukkan kedalam desikator selama 30 menit agar dingin lalu ditimbang berat cawan kosong. Selanjutnya melakukan halyang sama dengan ditambah 5 gram bahan simplisia daun kelor dan kulit jeruk nipis.

Lulur yang dibuat dengan berat masing-masing formulasi sebanyak 10 gram dibagi menjadi 2 kelompok, masing-masing ruangan dibuat 3 (tiga) formulasi untuk diuji pada kondisi penyimpanan dengan suhu yang berbeda yaitu suhu kamar dan suhu dingin, kemudian dilakukan uji kesukaan pada masing-masing formulasi. Susut pengeringan adalah pengukuran sisa zat setelah pengeringan pada temperature $105^{\circ} \mathrm{C}$ 30 menit atau sampel berat konstan, yang dinyatakan sebagai nilai persen (\%) [8]. Tujuannya untuk memberikan batasan maksimal (rentang) tentang besarnya senyawa yang hilang selama proses pengeringan (Depkes RI, 2000).

Nilai untuk rentang yang diperbolehkan terkait susut pengeringan yang dinyatakan kurang dari 10\%. Berikut hasil susut pengeringan simplisia daun kelor dan kulit jeruk nipis:

\section{Tabel. 1 Hasil susut pengeringan simplisia daun kelor}

Sampel Simplisia

\begin{tabular}{ll}
\hline Berat cawan kosong & 49,85 gram \\
\hline Bobot simplisia & 5 gram \\
\hline $\begin{array}{l}\text { Bobot cawan } \\
\text { kosong } \\
\text { + simplisia }\end{array}$ & 54,83 gram \\
\hline Kriteria bobot & $\begin{array}{l}27,425 \mathrm{mg} \sim \\
0,0274 \text { gram }\end{array}$ \\
\hline Penimbangan 1 & 54,51 gram \\
\hline Penimbangan $\mathbf{2}$ & 54,48 gram \\
\hline Penimbangan 3 & 54,46 gram \\
\hline $\begin{array}{l}\text { Persentasi hasil } \\
\text { susut }\end{array}$ & $7,4 \%$ \\
pengeringan & \\
\hline
\end{tabular}

Tabel 1 menunjukkan hasil susut pengeringan simplisia daun kelor. Susut pengeringan dilakukan dengan

menggunakan 5 gram sampel simplisia daun kelor. Proses susut pengeringan yaitu dengan cara menimbang sampai seberat 5 gram kemudian dimasukan ke dalam oven yang bersuhu $105^{\circ} \mathrm{C}$ selama 30 menit, kemudian dimasukkan kedalam desikator agar uap menyerap selama 30 menit lalu ditimbang. Proses tersebut dilakukan sebanyak 3 kali atau lebih yang menghasilkan beratnya konstan. 
Tabel 2. Hasil susut pengeringan simplisia

$$
\text { kulit jeruk nipis }
$$

\begin{tabular}{ll}
\hline \multicolumn{2}{c}{ Sampel Simplisia } \\
\hline $\begin{array}{l}\text { Berat cawan } \\
\text { kosong }\end{array}$ & 39,39 gram \\
\hline Bobot simplisia & 5 gram \\
\hline $\begin{array}{l}\text { Bobot cawan } \\
\text { kosong } \\
+ \text { simplisia }\end{array}$ & 44,35 gram \\
\hline Kriteria bobot & $22,195 \quad \mathrm{mg}$ \\
& \multicolumn{2}{c}{$\sim$} \\
\hline Penimbangan 1 & 43,86 gram \\
\hline Penimbangan 2 & 43,84 gram \\
\hline $\begin{array}{l}\text { Persentasi } \\
\text { hasil susut } \\
\text { pengeringan }\end{array}$ & $9,8 \%$ \\
\hline
\end{tabular}

Tabel 2 menunjukkan hasil susut pengeringan simplisia kulit jeruk nipis. Susut pengeringan dilakukan dengan menggunakan 5 gram sampel simplisia kulit jeruk nipis. Proses susut pengeringan sama halnya dengan proses susut pengeringan daun kelor yaitu cara menimbang sampai seberat 5 gram kemudian dipanaskan dengan oven yang bersuhu $105^{\circ} \mathrm{C}$ selama 30 menit, kemudian disimpan di dalam desikator agar uap menyerap selama 30 menit lalu ditimbang. Proses tersebut dilakukan sebanyak 3 kali atau lebih yang menghasilkan beratnya konstan.

Dari data diatas susut pengeringan yang diperoleh dari sampel daun kelor dan kulit jeruk nipis menunjukkan hasil persentase yang berbeda, untuk sampel daun kelor menunjukkan hasil persentase yaitu $7,4 \%$, untuk sampel kulit jeruk nipis menunjukkan hasil persentase yaitu 9,8\%. Dari semua sampel untuk hasil susut pengeringan pada simplisia daun kelor dan kulit jeruk nipis sudah termasuk kedalam kadar air kurang dari 10\% dengan 3 kali penimbangan.

Uji organoleptik dilakukan selama 3 minggu, pengujian organoleptik sediaan yaitu dengan mendeskripsikan warna, aroma dan tekstur pada suatu sediaan.

Pada hari ke-12 dengan suhu dingin warna dari F1, F2 dan F3 masih terlihat stabil. Namun pada pengamatan hari ke-15 sampai hari ke-21 warna dari F1, F2 dan F3 mengalami perubahan warna menjadi hijau kecoklatan hal ini karena tempat penyimpanan yang berbeda akan memberikan pengaruh yang berbeda terhadap tekstur, aroma dan warna dengan suhu dingin dan kelembaban yang tinggi. Kestabilan warna dari sediaan bertahan sampai 2 minggu. Pada hari ke-12 aroma dari F1, F2 dan F3 masih terlihat stabil. Namun pada pengamatan hari ke-21 mengalami perubahan aroma sedikit beraroma khas kulit jeruk nipis. Kestabilan aroma dari sediaan bertahan sampai 18 hari. Pada hari ke-1 sampai hari ke-21 tekstur dari F1, F2 dan F3 masih stabil dengan tekstur butiran kasar dari kulit jeruk nipisnya. Namun saat lulur digunakan sedikit lengket jika diraba. Kestabilan tekstur dari sediaan bertahan sampai 3 minggu.

Formulasi yang paling baik untuk penyimpanan di suhu dingin dilihat dari warna, aroma dan tekstur sediaan lulur bubuk yaitu F3 yang memiliki kestabilan warna yang bertahan sampai 2 minggu dengan warna hijau segar, untuk aroma dari F3 khas dari kulit jeruk nipis sangat tajam dan setelah digunakan aroma dari kulit jeruk nipis masih tercium aroma khas dan kestabilan aromanya bertahan sampai 18 hari, sedangkan dari tekstur F3 masih terlihat stabil yaitu butiran kasar dan saat lulur digunakan sedikit lengket jika diraba dan kestabilan tekstur bertahan sampai 3 minggu.

Hasil uji organoleptik sediaan lulur bubuk daun kelor, tepung beras ketan hitam dan kulit jeruk nipis yang telah diamati selama 3 minggu, pengamatan tersebut dilakukan selama 3 hari sekali. Uji Organoleptik yang diamati meliputi warna, aroma dan tekstur dalam uji ini setiap formulasi dibuat menggunakan 3 sampel dengan suhu yang berbeda.

Pada hari ke-9 dengan suhu kamar warna F1,F2 dan F3 masih terlihat stabil. Namun pada pengamatan hari ke-12 sampai hari ke-21 warna dari F1, F2 dan F3 mengalami perubahan warna menjadi hijau kecoklatan hal ini karena tempat penyimpanan yang berbeda, semakin tinggi suhu dan kecepatan aliran udara maka proses pengeringan berlangsung secara 
cepat. Kestabilan warna dari sediaan bertahan sampai 9 hari.

Pada hari ke-12 aroma dari F1, F2 dan F3 masih terlihat stabil. Namun pada pengamatan hari ke-15 sampai hari ke-21 mengalami perubahan aroma sedikit beraroma khas kulit jeruk nipis. Kestabilan aroma dari sediaan bertahan sampai 2 minggu.

Pada hari ke-1 sampai hari ke-21 tekstur dari F1,F2 dan F3 masih stabil dengan butiran kasar dari kulit jeruk nipisnya. Namun pada saat lulur digunakan sedikit lengket jika diraba. Kestabilan tekstur dari sediaan bertahan sampai 3 minggu.

Formulasi yang paling baik untuk penyimpanan di suhu kamar dilihat dari warna, aroma dan tekstur sediaan lulur bubuk yaitu F2 yang memiliki kestabilan warna yang bertahan sampai 9 hari, untuk aroma dari F2 khas kulit jeruk nipis tidak terlalu tajam dan kestabilan aromanya bertahan sampai 2 minggu, sedangkan dari tekstur F2 masih terlihat stabil yaitu butiran kasar dan saat lulur digunakan sedikit lengket jika diraba dan kestabilan tekstur bertahan sampai 3 minggu.

Perbandingan uji organoleptik sediaan yang disimpan pada suhu yang berbeda yaitu suhu dingin dan suhu kamar. Penyimpanan pada suhu dingin dan suhu kamar, F1, F2 dan F3 sediaan berwarna hijau akan tetapi mengalami perubahan warna menjadi hijau kecoklatan pada hari ke-15, aroma sediaan masih terdapat khas kulit jeruk nipis, tekstur dari sediaan lulur

pada saat digunakan dan diraba menjadi sedikit lengket. Sedangkan penyimpanan pada suhu kamar, F1, F2 dan F3 sediaan berwarna hijau akan tetapi mengalami perubahan warna menjadi hijau kecoklatan pada hari ke-12, aroma sediaan masih terdapat sedikit bau khas kulit jeruk nipis, sementara tekstur dari sediaan lulur pada saat digunakan dan diraba sedikit bau khas kulit jeruk nipis.

Hasil Uji Kesukaan untuk menentukan formula mana yang paling diminati, peneliti melakukan uji kesukaan kepada 20 responden dengan cara menyajikan 3 sampel formula dari sediaan lulur bubuk yang telah dibuat, kemudian para responden diminta untuk menilai warna, aroma dan tekstur dari sediaan lulur bubuk tersebut.

Hasil dari uji kesukaan untuk sediaan lulur bubuk didapat F3 yang paling banyak diminati dan dari segi warna paling disukai F2 karena memiliki warna yang hijau tidak terlalu kecoklatan, untuk segi aroma paling disukai F3 karena aroma khasnya dari kulit jeruk nipis saat digunakan dan setelah digunakan aroma khas kulit jeruk nipis tidak hilang. Sedangkan tekstur dari sediaan lulur bubuk F1, F2 dan F3 lebih disukai F3 karena teksturnya sedikit lengket saat diraba. Dapat dilihat pada Tabel 4.6 dan 4.7 yang menunjukkan bahwa baik warna, aroma dan tekstur F1,F2 dan F3 paling tinggi perolehan nilainya yaitu F3 dengan total yang paling disukai 13 panelis dan hasil persentase 65\%.

\section{PEMBAHASAN}

Sediaan lulur bubuk dari daun kelor, tepung beras ketan hitam dan kulit jeruk nipis dibuat dengan cara dikeringkan terlebih dahulu dibawah sinar matahari langsung sampai kering, karena sediaan yang dibuat bubuk jadi semua bahan dikeringkan lalu diblender dan diayak dengan ayakan no mesh 100 untuk mendapatkan kehalusan yang diinginkan. Setelah dikeringkan proses selanjutnya melakukan susut pengeringan daun kelor dan kulit jeruk nipis untuk mengetahui kadar air dari simplisia daun kelor dan kulit jeruk nipis memenuhi syarat atau tidak. Setelah memenuhi syarat simplisia, sediaan lulur bubuk dari daun kelor, tepung beras ketan hitam dan kulit jeruk nipis dilakukan proses pencampuran semua bahan sampai homogen. Untuk tahap selanjutnya, sediaan lulur bubuk disimpan pada suhu yang berbeda yaitu pada suhu dingin dan suhu kamar. Penyimpanan yang berbeda dilakukan untuk mengetahui ada atau tidaknya kestabilan pada sediaan lulur bubukyang disimpan selama 3 minggu.

Hasil uji organoleptik yang meliputi pengamatan warna, aroma dan tekstur dari sediaan lulur bubuk daun kelor, tepung beras ketan hitam dan kulit jeruk nipis diperoleh formulasi dengan penyimpanan pada suhu dingin yang paling baik dari warna yaitu F3 sediaan berwarna hijau segar dengan kestabilan warna bertahan sampai 2 
minggu, walaupun mengalami perubahan warna hijau menjadi hijau kecoklatan pada hari ke-15 sampai hari ke- 21, sedangkan warna yang paling baik dari sediaan lulur bubuk dari hijau menjadi hijau kecoklatan disimpan di suhu kamar terdapat pada F2 dengan kestabilan warna bertahan sampai 9 hari.

Untuk aroma yang paling baik dalam penyimpanan di suhu dingin yaitu sediaan lulur bubuk daun kelor, tepung beras ketan hitam dan kulit jeruk nipis terdapat pada F3 karena memiliki aroma khas kulit jeruk nipis yang stabil selama 18 hari. Sedangkan pada suhu kamar aroma yang paling baik yaitu F2 dengan aroma khas kulit jeruk nipis yang tidak terlalu tajam dan kestabilan aroma bertahan sampai 2 minggu. Selanjutnya penyimpanan di suhu dingin dari segi tekstur yang paling baik yaitu F3 dengan tekstur dari sediaan lulur saat digunakan sedikit lengket saat diraba dan kestabilan tekstur bertahan sampai 3 minggu dan tekstur paling baik dari suhu kamar yaitu F2 dengan kestabilan tekstur bertahan sampai 3 minggu. Hasil penelitian yang diperoleh pada suhu dingin semakin lama proses penyimpanan tekstur sediaan lulur bubuk menjadi sedikit lengket saat diraba. Sedangkan pada suhu kamar semakin lama tekstur sediaan lulur bubuk tidak terlalu lengket saat diraba. Hal ini dikarenakan semakin tinggi suhu dan kecepatan aliran udara maka proses pengeringan berlangsung secara cepat [9]. Perlakuan dengan penyimpanan yang berbeda akan memberikan pengaruh yang berbeda terhadap tekstur, aroma dan warna dari sediaan lulur bubuk. Selain pada suhu dingin, karena kelembaban juga tinggi, maka tekstur, aroma dan warna dari sediaan lulur bubukada sedikitperubahan.

Hasil uji kesukaan pada sediaanlulur bubuk yaitu F3 yang banyak diminati dengan hasil yang diperoleh lulur bubuk aman untuk digunakan oleh masyarakat. Sediaan lulur bubuk yang stabil terdapat pada penyimpanan suhu dingin dengan F3. Sediaan lulur bubuk teksturnya saat lulur digunakan sedikit lengket saat diraba, memiliki aroma khas kulit jeruk nipis yang dapat bertahan selama 18 hari dan memiliki warna hijau sampai hijau kecoklatan saat digunakan.

\section{SIMPULAN}

Berdasarkan hasil pengamatan dan analisis data yang dilakukan maka dapat disimpulkan bahwa sediaan lulur bubuk yang terbuat dari daun kelor dan tepung beras ketan hitam dengan penambahan kulit jeruk nipis untuk menambahkan aroma pada lulur. Lulur dibuat dengan cara dikeringkan sinar matahari langsung dengan menggunakan 3 formulasi yang berbedabeda yaitu daun kelor 1,3 gram, tepung beras ketan hitam 2 gram dan kulit jeruk nipis 6 gram pada F1, kulit jeruk nipis 7 gram pada F2 dan kulit jeruk nipis 8 gram pada F3. Hasil uji organoleptik yang dilakukan pada ketiga formula tersebut dapat dikatakan stabil. Berdasarkan hasil penelitian uji organoleptik yang paling baik penyimpanan di suhu dingin dari segi warna, aroma dan tekstur yaitu F3 dan pada suhu kamar dari segi warna, aroma dan tekstur yang paling baik yaitu F2. Hasil uji kesukaan didapat F3 yang disimpan di suhu dingin dengan komposisi daun kelor 1,3 gram, tepung beras ketan hitam 2 gram dan kulit jeruk nipis 8 gram adalah formulasi yang baik dan stabil.

\section{DAFTAR PUSTAKA}

1. Maysuhara, S. 2009. Rahasia Cantik, Sehat dan Awet Muda. Yogyakarta : Pustaka Panasea. 45-47

2. Oezil, F. 2014. Radikal Bebas, Antioksidan dan Penuaan. Padang : Universitas Andalas, Fakultas Kedokteran, Biokimia

3. Sutresno., dan Lisawati., 2011. Efek Pemberian Ekstrak Metanol Daun Kelor (Moringa Oliefera) meningkatkan Apoptosis Padas el Epitel Kolon Tikus (Rattus Norvegius) Wister yang di induksi 7.12 Dimetilbenz (a) antrasen (DMBA). Malang : Skripsi Universitas Brawijaya.

4. Kasolo JN, Bimeya GS, Ojok L, Ochieng J, Okwal-okeng JW. 2010. Phytochemicals and Uses of Moringa Oleifera Leaves in Ugandan Rural Communities Josephine. Journal of Medicial Plants Research 6(2): 753757.

5. Rajanandh MG dan Kavitha J. 2015. Quantitative Estimation of $\beta$ Sitosterol, Total Phenolic and 
Flavonoid Compounds in the Leaves of Moringa Oleifera Quantitative Estimation of $\beta$-Sitosterol, Total Phenolic and Flavonoid Compounds in the Leaves of Moringa Oleifera. Journal, International Pharmtech 2(2): 14091414.

6. Budiman AY. 2012. Substitusi Parsial Tepung Terigu Dengan Tepung Beras Ketan Hitam Pregelatinisasi Pada Pembuatan Cookies. Skripsi. Program Studi Teknologi Pangan. Fakultas Pertanian. Universitas Katolik Widya Mandala Surabaya

7. Ahira, Anne. 2013. Kandungan Jeruk Nipis dan Manfaatnya. Online: http://www.anneahira.com/. Diakses pada 29 November 2019.

8. Departemen Kesehatan RI. (1995) Farmakope Indonesia Edisi IV. Jakarta: Departemen Kesehatan RI.

9. Rukmana,R. (1996). Jeruk Nipis. Kanisius : Yogyakarta. 